\title{
JRPR as a Research Information Platform, Being a Symbol of Inter-Academic Collaboration across Borders
}

\author{
Takeshi IIMOTO, Editor-in-Chief, JRPR, Vice-President of Japan Health Physics Society (JHPS) \\ Division for Environment, Health and Safety, The University of Tokyo
}

\section{Editorial}

\footnotetext{
This is an Open-Access article distributed under the terms of the Creative Commons Attribution NonCommercial License (http://creativecommons.org/ licenses/by-nc/3.0) which permits unrestricted noncommercial use, distribution, and reproduction in any medium, provided the original work is properly cited.

Copyright $\odot$ 2019The Korean Association for Radiation Protection
}

The nuclear disaster of Fukushima Daiichi Nuclear Power Plant seems to have dramatically expanded the range of public expectations for "radiation protection" as a specialized area. Academic approaches from a scientific or technical perspective sometimes require wider, deeper and more detailed discussions. The traditional academic approach was criticized as completely lacking for the viewpoints of outreach, ethics, and consensus. Therefore, there are now strong expectations for areas that do not seem to exist within the scope of traditional radiation protection and for the discovery of new human resources. In addition, strong cooperation with new areas and human resources is strongly demanded in our field.

Radiation and radioactive materials are surely typical risk sources. The "radiation protection field", which deals with "state-of-the-art" risk management in very complex situations, is a field with the highest level of practice. We try case studies and research and develop processes for innovative advancement of general risk management. The field of radiation protection is also a treasure trove of STREAM (Science, Technology, Robotics, Engineering, Arts, and Mathematics), which is a keyword in the latest education field. Our daily research and activities are full of attractive subjects and examples for next-generation education. The combination of these and the successful in developing research on outreach methods may significantly improve the power of our message to citizens including the next generation.

We, Japan Health Physics Society (JHPS), are actively working to set up two special items by the Board of Directors: (1) strengthening international collaboration activities and (2) developing next-generation experts. Through mutual dispatch of experts and young researchers to annual conferences hosted by academic societies in various countries, we are activating human resource exchange and information sharing from an international perspective. I hope that this international joint journal "JRPR" will function effectively and powerfully as one of the information platforms of the research trends. As one of editor-in-chief representing JHPS, I would like to actively use JRPR as an opportunity to introduce new fields and human resources. I want our stakeholders to understand the characteristics of our journal on free JRPR submission fee for young researchers. We JRPR are waiting for your research results or articles with strong messages to the world. I look forward to your strong communication and active international exchange in the Asia-Pacific region, centered on the three academic societies of KARP, JHPS, and ARPS. 